\title{
Simulation games that integrate research, entertainment, and learning around ecosystem services
}

\author{
Robert Costanza $^{\mathrm{a}, *}$, Karim Chichakly ${ }^{\mathrm{b}}$, Virginia Dale ${ }^{\mathrm{c}}$, Steve Farber ${ }^{\mathrm{d}}$, David Finnigan ${ }^{\mathrm{e}}$, \\ Kat Grigg ${ }^{f}$, Scott Heckbert ${ }^{g}$, Ida Kubiszewski ${ }^{a}$, Harry Lee ${ }^{e}$, Shuang Liu ${ }^{\text {h }}$, \\ Piotr Magnuszewski ${ }^{i}$, Simone Maynard ${ }^{j}$, Neal McDonald ${ }^{\circ}$, Richard Mills ${ }^{c}$, Sue Ogilvy ${ }^{a}$, \\ Petina L. Pert ${ }^{\mathrm{m}}$, Jochen Renz ${ }^{\mathrm{n}}$, Lisa Wainger ${ }^{\mathrm{k}}$, Mike Young ${ }^{\mathrm{p}, \mathrm{q}}, \mathrm{C}$. Richard Ziegler ${ }^{1}$ \\ a Crawford School of Public Policy, Australian National University, Australia \\ b ISEE Systems, USA \\ c Oak Ridge National Lab, USA \\ ${ }^{\mathrm{d}}$ University of Pittsburgh, USA \\ e Independent Game Designer, UK \\ ${ }^{\mathrm{f}}$ University of Queensland, Australia \\ ${ }^{g}$ Alberta Innovates, Canada \\ h CSIRO Ecosystem Sciences, Australia \\ ${ }^{\mathrm{i}}$ Centre for Systems Solutions, Poland \\ ${ }^{\mathrm{j}}$ Fenner School of Environment and Society, Australian National University, Australia \\ ${ }^{\mathrm{k}}$ University of Maryland Center for Environmental Science, USA \\ ${ }^{1}$ United States Environmental Protection Agency, Office of Research and Development, USA \\ ${ }^{\mathrm{m}}$ Centre for Tropical Environmental and Sustainability Science, School of Earth and Environmental Sciences, James Cook University, Cairns, \\ Queensland, Australia \\ ${ }^{\mathrm{n}}$ Research School of Computer Science, Australian National University, Australia \\ ${ }^{\circ}$ University of Maryland, Baltimore City, USA \\ ${ }^{\mathrm{P}}$ University of Adelaide, Australia \\ ${ }^{\mathrm{q}}$ Harvard University, USA
}

\section{A R T I C L E I N F O}

Article history:

Received 13 July 2014

Accepted 29 September 2014

Available online 7 November 2014

Keywords:

Computer games

Choice modeling

Valuation

\begin{abstract}
A B S T R A C T
Humans currently spend over 3 billion person-hours per week playing computer games. Most of these games are purely for entertainment, but use of computer games for education has also expanded dramatically. At the same time, experimental games have become a staple of social science research but have depended on relatively small sample sizes and simple, abstract situations, limiting their range and applicability. If only a fraction of the time spent playing computer games could be harnessed for research, it would open up a huge range of new opportunities. We review the use of games in research, education, and entertainment and develop ideas for integrating these three functions around the idea of ecosystem services valuation. This approach to valuation can be seen as a version of choice modeling that allows players to generate their own scenarios taking account of the trade-offs embedded in the game, rather than simply ranking pre-formed scenarios. We outline a prototype game called "Lagom Island" to test the proposition that gaming can be used to reveal the value of ecosystem services. Our prototype provides a potential pathway and functional building blocks for approaching the relatively untapped potential of games in the context of ecosystem services research.
\end{abstract}

(c) 2014 Elsevier B.V. All rights reserved.

\section{Introduction}

Games have been popular throughout human history to educate and entertain. Even the simplest of games can be thought of as simulations of some aspect of life. Some of these simulations can be

\footnotetext{
*Corresponding author. Tel.: +61026125 6987.

E-mail address: Robert.Costanza@anu.edu.au (R. Costanza).
}

quite complex and useful. Examples include war games and flight simulators. Games that can be used for research to understand some aspect of human behavior have also become quite popular and useful. For example, Von Neumann and Morgenstern (1953) formulated much of economic behavior around "games of strategy." More recently, the Prisoner's Dilemma game has been used extensively to understand the evolution of cooperative behavior. A search of the ISI Web of Knowledge for the topic "prisoner's dilemma" turned up over 1700 papers. The most frequently cited of these was 
the 1981 article by Axelrod and Hamilton (1981). In 2002, Vernon Smith was awarded the Nobel Prize in Economics for his pioneering role in the development of experimental economics, which, in essence, uses simple games to test behavioral responses to different value propositions.

Rapidly advancing technology has provided the increasing ability to bring realistic detail to recreational computer games. Imagine such a game that also offers academically rigorous, peer-reviewed representations of Earth's attributes including human interactions. Millions of players could test and provide solutions to problems that challenge policy analysts, corporate executives, climate scientists, philanthropists, economists, government leaders, sociologists, and scenario planners

The promise of games that integrate research, education and entertainment is huge, but has rarely been achieved. One of the few examples is the "World Game" first developed in 1961 by Buckminster Fuller, originally as a global simulation alternative to war games. The World Game allows a group of players to cooperatively develop a set of global scenarios. The goal is to "make the world work for $100 \%$ of humanity in the shortest possible time through spontaneous cooperation without ecological damage or disadvantage to anyone", thus increasing the quality of life for all people. The World Game has been played by thousands of people, with and without the aid of computers over the years. It is now offered by osearth.com as a global simulation game for 40 to 600 players in educational workshops. Another recent example is an extension to a very popular board game "Settlers of Catan" called "Catan: Oil Springs" (Griswold, 2013).

We now have the capability to link relatively sophisticated computer simulations with engaging game interfaces over the internet, allowing us to observe and record player behavior. Harvesting such information - or crowdsourcing - from games may help answer both basic and complex research questions, while at the same time entertaining and educating game players. In this paper we outline a novel approach for integrating research, educational and entertainment outcomes within a gaming environment, focusing on and facilitating exploration of the valuation of ecosystem services - that is, on those processes and functions of ecosystems that benefit human society. To date, while some popular games broadly explore aspects of ecosystem science incorporating educational outcomes or could be modified to do so (e.g. SimCity, Civilization, Myst), there is a huge opportunity to better integrate such interfaces with research.

In this paper we review the use of games in research, education, and entertainment and develop ideas for integrating these three functions around the idea of ecosystem services valuation. We start by reviewing the attributes of digital games that allow them to be useful for research, and then explore whether and how games with these attributes could also be made entertaining enough to induce a large number of people to voluntarily play them. This would open up vast new possibilities for social science research. We also explore the educational by-products of such integrated games. We then explore the relationship between the attributes of our hypothetical integrated game and existing games, and the functional attributes that would be needed in games aimed at valuing ecosystem services. We conclude with an outline of a hypothetical game that would satisfy our requirements and sketch the research outcomes that might be expected from such a game.

\section{Attributes of digital games for research}

There are several attributes that a gaming system should possess in order to simultaneously meet the goals of entertainment, education, and research toward valuing ecosystem services.
Fig. 1 is a conceptual diagram showing the basic elements of an integrated game and the potential research results that such a system might provide. These include insights into human decision-making and valuation of ecosystem services, but also improving our technical ability to link models and game interfaces. There is also the knowledge transfer and educational benefits that individuals will gain from playing the game and that will also influence their behavior in the game (Verutes and Rosenthal, 2014). If the game can be designed as engaging and entertaining enough to get many people to voluntarily play it, then the research and education goals can also be met.

Perhaps the easiest way to start is to describe the criteria for use of the system for research purposes, and then explore whether such an integrated system could also be made entertaining and educational.

\subsection{Research on decision-making and valuation}

Ecosystem services are defined as the contributions of ecosystems (natural capital) to human well-being (Costanza et al., 1997; Millennium Ecosystem Assessment (MEA), 2005). Valuing ecosystem services is complex and difficult. It requires assessing the relative contribution of natural capital to human well-being, in interaction with the other three major forms of capital - built, human, and social (Fig. 2). It is therefore inherently a transdisciplinary endeavor. Valuation requires both the conveying and the collection of information from many people. Gaming offers the opportunity to do this for a larger and broader cross-section of the population than typical valuation approaches.

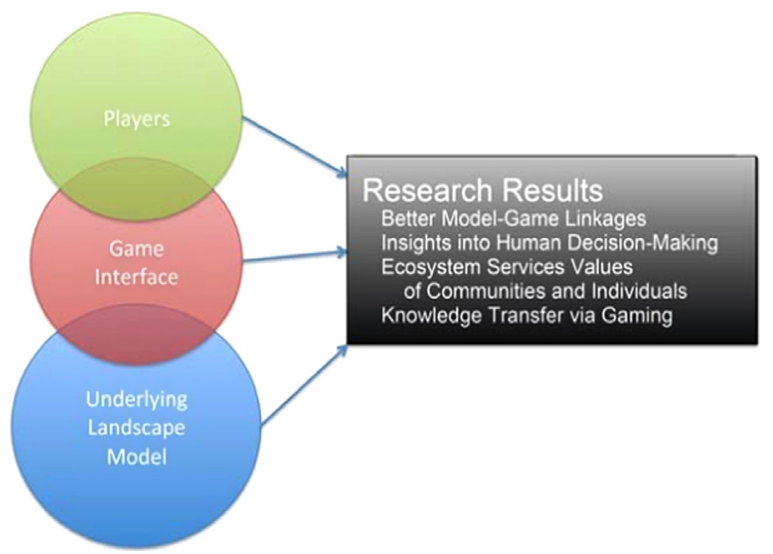

Fig. 1. A framework for the use of gaming for landscape research.

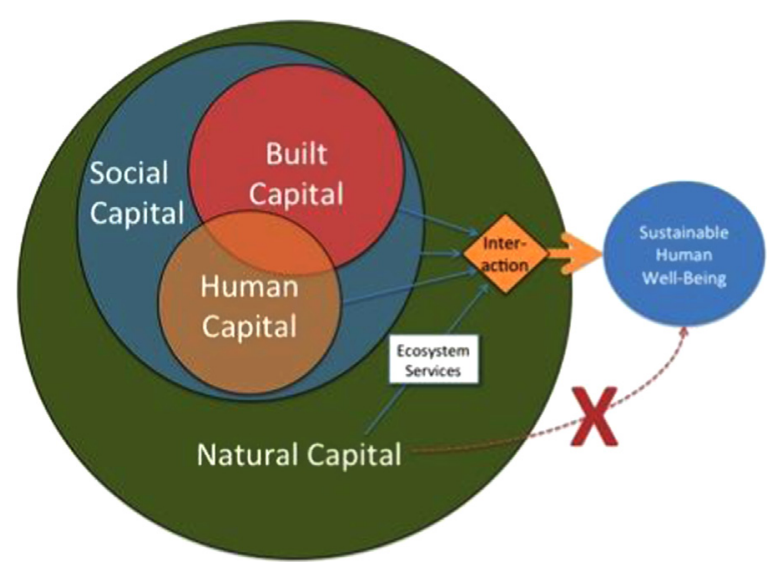

Fig. 2. The interactive contribution of 4 basic types of capital to the production of human well-being. 
Approaches like contingent valuation, which involves asking people directly how much they would be willing to pay for ecosystem services, have many limitations (Liu and Stern, 2008). These include the imperfect information individuals have about ecosystems and their connections to human well-being and their discomfort with stating trade-offs for ecosystems in monetary units. Choice experiments, where individuals are asked to rank alternative scenario outcomes, seem to be an easier way for people to think about trade-offs (Farber et al., 2002). But usually in these experiments the scenarios are static and the sample sizes are small. The degree of replication needed to produce an estimate of value is achieved by sending different versions of the scenarioranking questionnaire to a number of participants.

Moving the experiment into a computer-based system allows the participants to make decisions based on information provided by a user interface, and allows for information and the resulting behaviors to be presented rapidly, allowing more information provision, decision making points, and greater number of repeated trials. Behind the user interface, the computer-based experiment can be connected to a dynamic simulation model that updates the game's database as decisions are made (Fig. 1). Janssen et al. (2010) conducted a series of computer-based experiments to test the impact of communication and punishment in common-pool resource management, finding that respondents are willing to engage in punishing defectors even at personal cost; however punishment without communication does not increase overall payoffs. Manson and Evans (2007) present a dynamic spatiallyexplicit model of reforestation and agricultural land use change where experiments were used to compare participants' behaviour with those of programmed agents, finding that human decision makers do not necessarily allocate land uses to optimize payoffs.

There are many game systems that have been developed or are under development that incorporate various aspects of environmental decision-making (see, for example, ecogamer.org/environmentalgames and Verutes and Rosenthal (2014)). Most of these are aimed at combining education with entertainment. So far few of these games have incorporated a significant research component.

One example is Heckbert and Bishop (2011), who present an integrated GIS-based agent-based model and an experimental economics platform where participants take on the role as an agent, or avatar, in a dynamic simulation model of agricultural land management. This example shows the progression of experiments towards multi-player gaming, however, experimental economics usually recommends omitting context and complexity from the decision making situation in order to isolate the influence of a given tradeoff decision. For example in the Heckbert and Bishop (2011) application, experiment participants applied 'inputs' to 'production' rather than 'fertilizer' to 'agriculture' to avoid social biases regarding the system they were managing. In Janssen et al. (2010) participants used an abstract gridded board with tokens to represent a common-pool resource - not unlike common board games (e.g. backgammon, checkers, go).

\subsection{Using games to value ecosystem services}

Decisions that relate to sustainability are inherently imbued with social biases, and it is arguably the social context of the decision making situation that dominates and/or influences real-world decision makers. In the online gaming environment envisioned in this paper, players would be allowed to see the implications of their choices in a much more vivid and dynamic manner and, hence, have the potential to make much more informed and considered choices. This recognizes that the environmental and social context is an important driver in decision making. Users can also learn about the ecosystem of interest from playing the game and construct their preferences based on better knowledge than they had at the start. If choices are more considered and informed, then resultant estimates of value - as revealed by gameplay - may be more reliable.

Dynamic modeling's strength is simulating links between human decisions and ecosystem functioning, but, used alone, it still lacks the human component. Thus, for research purposes, we would like to have an interactive gaming platform on top of an ecosystem simulation model that would allow individuals to "play" the system to create their version of the "best", the highest quality of life, world. Since the model can embed the trade-offs between, for example, a better environment and food production, the choices players make during the game will reflect how they value tradeoffs like these. Information that reveals the nature of interactions among players may also prove useful. This is somewhat like a conventional choice experiment (Colombo et al., 2011; Wilson and Carpenter, 1999), except that players are able to create their own scenarios rather than the researcher presenting them with a fixed set. Preferences can also emerge as a result of learning about the system or from group interactions.

Therefore the games should be designed to permit inferences of player preferences for a manageable number of ecosystem services, and the responses of those preferences to changes in game parameters and interactions with other players. The underlying hypothesis is that preferences are not fixed but are "constructed" (Slovic, 1995) through the process of learning, in this case while playing a game. In an ideal world, the results derived from this proposed methodology could be compared with data from a static choice experiment designed to elicit the same estimates of value.

\subsection{Integrated modeling}

What people value in terms of the environment may be a specific component of an ecosystem (i.e. iconic species such as koalas, or timber and fiber resources), the whole of the ecosystem (i.e. recreational opportunities, spiritual and religious values), or the connection of ecosystems across a specified area (i.e. flood regulation within a catchment). However, the processes (e.g. the regulation of hydrological flows, the movement of floral gametes), underpinning these values generally occur at the landscape scale and above, and to receive the benefits derived from an ecosystem service usually involves an interaction among natural, built, human, and social capital (Fig. 2).

Therefore a useful game for ecosystem services valuation would need to focus on spatial scales from local to global, time scales from short-term to long-term, and would need to include systems with some representation of the four types of capital. A key question is that of how to change the mix of the various forms of capital available. The game must also allow for individual and group decision making as sustainability challenges often involve public/private tradeoffs, and the scale of group decision making is often misaligned with spatial and temporal scales. There is substantial literature on simulation modeling for ecosystem services at these scales that can form the basis for these games (Boumans et al., 2002; Costanza and Voinov, 2003; Arkema and Samhouri, 2012; Nelson et al., 2009; Craft et al., 2009), but these models have yet to be used for integrating gaming as shown in Fig. 1.

One recent effort that may form the basis for an integrated gaming system of the type we envision is the MayaSim model developed by Heckbert (2013). MayaSim is a spatially explicit combined systems dynamic and agent based-model of the rise and fall of the Maya civilization in the Yucatan Peninsula of Mexico. It contains all four types of capital needed to assess ecosystem service tradeoffs and the ability for players to interact with the model on the fly and change parameters and policies. Spatial and temporal patterns operate at multiple scales, which is an important consideration, as the users of the game envisioned in 
this paper would need to learn to balance local versus global and short term versus long term effects of decision making. This type of model is what we have envisioned as the basis for our prototype discussed below.

\subsection{Eliciting realistic choices/preferences}

One important criterion for use of games for research purposes is that an individual's behavior in the games should be relatively similar to their behavior in "real" situations. Although there is an implicit assumption in experimental economics lab experiments using games that behavioral patterns identified through these experiments can be in some way generalized to other (real world) situations, demonstrating this relationship is far from trivial. Levitt and List (2006, 2007) provide a critique of this assumption identifying several factors influencing lab behavior (other than financial incentives) that may strongly differ from real life situations: presence of moral considerations, effect of scrutiny of one's actions by others, context in which decisions are embedded, self-selection of participants, and stakes of the game. Similarly, generalizing outcomes of the games for valuation of ecosystem services, requires one to consider these and possibly other factors, and should be based, as Levitt and List suggest, on appropriate theory. In spite of these concerns there have been attempts to demonstrate empirically the validity of experimental games research to real world situations (Rustagi et al., 2010, Baran et al., 2010). Especially important for this article is the study by Castronova et al. (2009) of the transaction data of the EverQuest 2 virtual world (massively multiplayer online role-playing game), demonstrating that virtual economic behavior follows real-world patterns.

We recognize that attempting to elicit preferences from individuals or groups may suffer from the artificiality of the preference elicitation procedure. Like all preference elicitations short of observing real world behaviors, preferences revealed in surveys or games, whether they involve contingent valuation or more sophisticated choice designs, may be significantly impacted by the context of the designs themselves. In one very important sense, however, this is not necessarily a bad thing. We want to use the game to help people learn about ecosystem services and "construct" their preferences based on the new information they receive. This dynamic interplay between players' decisions and processes embedded in game mechanics, also referred to as "procedural rhetoric" (Bogost 2007), can be the games' unique feature to allow researchers more adequate elicitation of preferences. In addition, our research goal is not to place so much emphasis on the preferences we observe in the game, as to observe how those game-playing preferences change under different gaming conditions. These conditions would include the number of times a player plays, the relative magnitudes of ecosystem services, how much information the player is given, the game scoring mechanics, and other factors.

In a gaming environment, we can test the effectiveness of techniques that have been suggested to increase the realism of player behavior, including:

- Many game players when encountering a new game will try to "break" the game by exploring extreme, unrealistic, settings. One can arrange the game to have several levels, with a certain level of skill and understanding required to advance to the next level. One can then allow players to experiment with the game at level 1, and only begin to collect data once they have advanced to level 2 and beyond. In any case, we can observe how player choices vary with experience playing the game.

- Games structured around more realistic situations and environments have been hypothesized to elicit behavior that is more consistent with behavior in the real world (De Lucia et al., 2009).

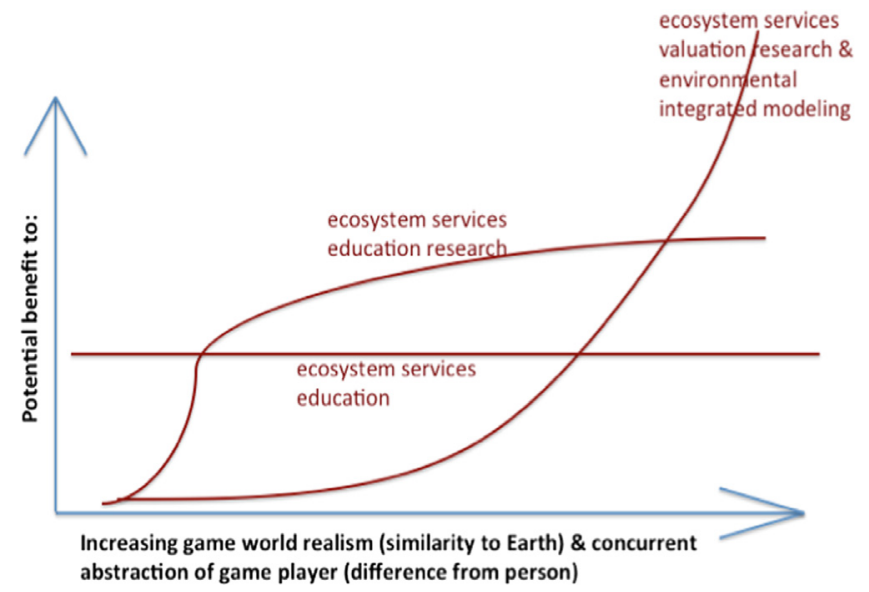

Fig. 3. Relationship between realism and opportunities to collect useful information from games.

For example, Fiore et al. (2009) claim that "This should provide tools for policy analysis and research on decision making that combine the inferential power of replicable experimental treatments with the natural "look and feel" of a field domain." Fig. 3 shows how this might work. One could use a series of versions of a game to test how the use of more realistic environments as the basis for the games changes player behavior.

- Players might take games more seriously if they are playing for points, badges, or some other reward. One can include these kinds of rewards in some versions of the game in order to test how it changes player behavior. Clearly, such an arrangement would not be appropriate for the elicitation of baseline choices/ preferences, where researcher should try to minimize the influence of their values on player's decisions.

- A simulation of the real world is necessarily a simplification of the world. Ecosystem services in such a simplified world may have unintended side-effects that do not occur in the real world. Participants might exploit weaknesses or loopholes in the model in order to achieve their personal goal of winning or collecting badges, etc. Another danger is that participants intentionally or unintentionally play the strategies that are preferred by the domain experts and game designers, and as such players may be guided towards the outcomes the designers want to achieve. One possibility of avoiding such unintended outcomes is to translate the game tasks into a game that does not closely match the desired tasks. An example of this is verigames.com where the task of players is to identify potential bugs in software, but the games have no obvious connection to this task and players are not required to have any expertise in software development. Such a translation is very difficult for ecosystem services. While it is certainly possible to translate individual services, translating the interplay and interactions between different services seems impossible. Therefore, simulation games, despite the potential disadvantages, seem to be the most appropriate way of putting ecosystem services into a game. What is important is to be aware of these risks and to mitigate them.

\section{Entertainment and education}

Making a game that is useful for research also entertaining and educational seems to be eminently possible, but so far has been rare. There are exceptions. SimCity produces a relatively realistic urban growth simulation and is very popular, entertaining, and educational. Adding the research components mentioned above to 
a game like this is conceivable. Such a game would also have an educational component as a by-product, since it would allow players to better understand the tradeoffs inherent in urban decision-making.

There is clear potential for scientists to use computer games as educational tools about ecosystem services. By offering players the opportunity to manage a landscape, a game can promote key concepts underlying ecosystem services frameworks in practical hands-on scenarios. The goal is to engage players in designing better institutions, better environments and therefore a better world. Recent evidence suggests that pro-social games can positively influence pro-social behavior (Gentile et al. 2009) one can expect a similar effect with respect to pro-environmental behavior.

Players should develop an understanding of some or all of the following:

- The implications of human activities on ecosystems.

- The trade-offs inherent in managing ecosystems, win-win solutions and the implications of compromise.

- The idea that humans do not exist apart from the environment.

- Ideas of tipping points, regime shifts, non-linear collapse (things could look like they're going fine for a while and then suddenly collapse).

- Some activities can create irreversible changes in ecosystems (path dependence).

- Unintended consequences - your mental model may be very different from how the system actually works.

- Cooperation may be critical to avoid social traps and commons dilemmas.

- The impacts of environmental collapse may be unequally socially distributed.

\section{Relationship to existing games}

Fig. 4 shows the relationship between game "playability" or popularity and the potential use of the game for ecosystem services valuation. There are a number of popular and playable games that are potentially useable after modification for research purposes. Examples include SimCity, CityOne, and Civilization. SimCity has some of the attributes needed for use as a research game on ecosystem services, but especially the natural capital components of the game would have to be greatly expanded. Farmville is also an interesting example at the farm scale, but it would have to be expanded to include entire landscapes.

Experimental economics games are useful for ecosystem services valuation, but are not very playable or popular. Examples

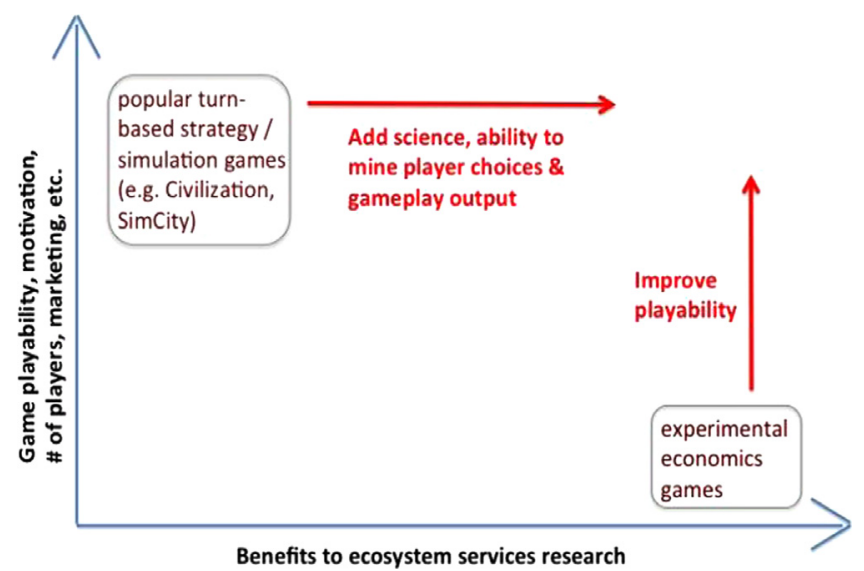

Fig. 4. Hypothesized relationship between playability and benefits to research. include: the prisoners' dilemma (Axelrod and Hamilton, 1981), the dollar auction (Costanza and Shrum, 1988), common pool resources games (Ostrom et al., 1994) and many others. These games could be made much more playable, but their scope would have to be greatly expanded. The vision is one that involves hundreds and preferably thousands of players rather than twenty or so typically involved in experimental economics.

What we are after are games in the upper right corner of the diagram. Games which are both playable and popular and also useful for research on ecosystem services valuation. Currently that space is almost blank (one possible exception might be the World Game mentioned earlier). We can get there via either of the arrows in the figure - modification of existing games - or by constructing new games that are built specifically for this purpose. Below we describe briefly what such games might look like.

\section{Functional attributes of games to value ecosystem service}

A game designed to value ecosystem services must thus have a number of attributes. The basic idea of the game is to allow people to construct their own scenarios via investment and management choices and use their choices to infer their value priorities.

Given that ecosystem services are the benefits to people of functioning ecosystems (natural capital) in combination with built, human and social capital, the game must therefore minimally have some representation of these four general types of capital and their interaction to produce human well-being (Fig. 2). The game needs to be able to accommodate players' choices at two levels:

1) Weights for different types of capital representing players' understanding and preferences (values) with respect to long-term sustainable well-being.

2) The ability for people to make choices about how to invest limited resources in each of these types of capital at points in time, and how to manage the integrated system.

These choices represent the tradeoffs players are willing to make to maximize their sustainable well-being as they understand it, that becomes the explicitly stated purpose of the game. Players also need to see how well they are doing as the game progresses, both in terms of the levels of the stocks and flows in the system and, potentially, an aggregated index of well-being. An alternative would be for the game itself (based on expert and/or game player assessment) to weigh the various elements and display the aggregate index. One could then see if providing a weighted index had an influence on the player's decisions. This is an example of one type of experiment that could be performed within the game environment. Such externally imposed values could also be used in the educational mode of the game.

\section{An example: "Lagom Island"}

For illustrative purposes only, below we describe a game, Lagom Island, that might be used to test some of these ideas. "Lagom" is a Swedish word that means "just the right amount." The origin is from old Viking tales about passing a horn full of mead around the campfire and everyone taking just the right amount, so that there was still some left for the last in the circle. Lagom Island is a turn-based resource management simulator in which the player manages an island with the goal of creating the "right" landscape - a sustainable and desirable island.

The game would begin with either a blank slate or a degraded landscape so that players are not punished for interfering with an already perfect environment. The player takes control of a group of 
settlers arriving by boat to the island - they may be climate refugees, or their identity may be undefined. When the settlers arrive on the island at the mouth of a river. The rest of the island is hidden from them. To begin with, game time moves at a rate of one month per turn, but after a while it will speed up to a rate of 6 or 12 months per turn.

The player has a suite of actions and resources that they can use to make decisions about "development" or "habitation" of the island. They may direct agents to undertake tasks, including altering land use. The player's first priority is to obtain food and water. Initially, they can begin by utilizing water from the stream and fishing. Within a short time and unless appropriate action is taken, large numbers of settlers get sick and die. The player will need to use water purification methods, then build purification centers, then eventually artificial wetlands. To begin with, the player's priority is to meet the settlers' basic needs and for the population to reach a replacement level.

Once they have satisfied their populations' basic needs, players are offered a range of projects to pursue. These might include challenges such as cultivating wine, domesticating local species, growing livestock to provide alternative foods ('a chicken in every pot'), manufacturing consumer goods, developing new kinds of agents, unlocking specific achievements and so forth. Some of these projects might be feasible within the limitations of a sustainable ecosystem, others will exceed these resources. As well as changing land use, players can impose zoning regulations. For instance, if fish stocks are beginning to collapse, players can limit activities around that area until the resource pools recover. In a sophisticated version of the game seasonal quotas could be set and managed via the introduction of fishery shares.

The player can allocate agents to different activities, from farming to fishing to collecting resources. Agents are semiautonomous but the player can impose limitations and rules on their behavior. At points, users can directly take control of specific agents or groups of agents. There are multiple different crops that can be harvested and at a certain point livestock can be introduced. They can pursue a range of possible strategies, from focusing on minimal environmental impact and keeping development within narrow constrictions, to focusing on building capital and having a damaging impact on the natural ecosystems. If you choose to degrade the system by, for instance, cutting down half the forest, you might get a message flagging what you're gaining in wood but also what you are losing in services, such as increased erosion and risk of flooding. Other variations of the game would not give you any advance warnings about the consequences of your decisions. Random effects such as illness, famine and war can kill settlers or otherwise interrupt other activities.

The game includes a predefined scoring index that translates elements such as food, housing, waste treatment and recreation as currency into the game. There is also a user-defined happiness index, in which the user sets up their own reward system by ranking their priorities, such as consumer goods or biodiversity. The game will rank players against the pre-determined metrics, as well as their own index.

There is an analytic tool embedded into the game whereby players are occasionally asked to report on the state of their island to a ruler in their place of origin. These reports may include predictions about the results of their actions. They can guess the outcome of their actions and if they are correct, they will receive extra points. These surveys will provide data to the game developers.

At a point in the game, players receive communication from another island - these could be run by computer-controlled agents or by other players; integrated online social networks could facilitate this type of interaction. These other islands would offer opportunities to trade. Islands have unequal resource distributions so that there are potential opportunities for trade. Prices for resources can be pre-determined by the game or set by players. As players are rewarded for trading goods, there may be a temptation to focus on the most profitable goods and focus on a particular industry, until their economy and/or ecosystem is a monoculture and therefore more fragile and less resilient.

When there are multiple islands, the game also includes migration. Settlers can move to islands with work, luxury items and consumer goods. The influx of settlers will improve those islands' work-forces, but at the same time apply more pressure to their ecosystems. Equally, other islands whose settlers have departed will have fewer pressures on their systems. Gradually other islands come into play - there are no necessary limits to the number of islands that can interact. If an island society collapses, the players will be able to start again on a new island, or rebuild their current habitat with an influx of new settlers. The game can continue indefinitely, but a key data point will be the state of the island when the players conclude.

\section{Research outcomes}

The key goal for the kind of games we are talking about is to capture revealed preference data from players. Through players' behavior in the game, we can infer the value that players place on different ecosystem services. In the normal framework of economic choice experiments, subjects are asked to choose between different static scenarios that have different levels of the key attributes of interest.

In the game, players would reveal their preferences for various elements of an ecosystem through managing trade-offs between these elements in a dynamic, whole systems, framework. The key assumption for this research goal is that you can derive from people's preferences for different scenarios within a game some information about the value they would place on those scenarios in the real world.

\subsection{Research questions}

The following are examples of questions that we would like to answer through this game:

- How do players assess and measure the value of ecosystem services? Traditional approaches survey people about values (i.e. contingent valuation) or ranking of fixed scenarios (i.e. choice modeling). We allow them to construct their own scenarios. The choices they make about resource investments and weighting of indicators tell us about the value they place on natural capital and ecosystem services.

- How, why, and when do these values change over time? In a game environment we can observe all the choices that people make and analyze that data.

- What influences people's choices about trade-offs between and among natural, built, human, and social capital assets?

- How does uncertainty and randomness affect choices? i.e. storms, toxic spills, political upheavals, epidemics, etc.?

- How does the amount, quality and timing of information affect decisions that people make?

- How much does interacting with others affect those decisions?

- Do players develop their preferences differently when playing individually, or in a group?

- How do players behave in a single-player vs. multiplayer experience? 


\subsection{Research advantages and disadvantages}

The advantages of using a computer game to capture data about preferences include:

- The ability to quickly replicate experiments.

- A large potential data pool, with potential sample sizes at least in the thousands.

- The ability to track and record player decisions through in-built survey mechanisms.

- Removing a degree of interviewer bias by enabling users to interact directly with an experiment rather than via an interviewer (albeit, the experiment is one step removed from the game developers or surrogate interviewers).

- The ability to place people's choices within contexts that are (potentially) more realistic than the typical context-neutral experimental form.

- Assessing whether increasing degrees of game 'realism' (complexity), or introducing different elements within a game, affects people's valuations and preferences?

Some potential disadvantages of this approach include:

- The unresolved question of whether players will value things in the game context in the same way they do in real life (this problem is also applicable to experimental economics studies, so is not unique to this project).

- The structure of the game, the game mechanics, and the reward structure will heavily prime people to give particular responses, regardless of their own preferences.

- There may be a tension between game's ability to be entertaining, to achieve educational goals, and to capture research data.

A potential method to control for the biases inherent in this form of data gathering is to measure player behavior in different variations of the game (e.g. some with ecosystem services described more explicitly, some with them more invisible), by comparing gameplay results from anonymous and non-anonymous players over online social networks, or by measuring people's behaviors in the game following different degrees and varieties of priming.

\section{Conclusions}

If the integrated gaming approach works, it could revolutionize the study of ecosystem services. By combining our scientific understanding of how ecosystems function (embedded in dynamic landscape models) with the ability to quickly and cheaply solicit input from a broad range of participants, this approach could have a huge impact on how ecosystem service valuation is done. This would dramatically improve our ability to understand and manage ecosystems and benefit society at large.

\section{Acknowledgments}

This paper is one of the results of workshops held at the National Socio-Environmental Synthesis Center (SESYNC) at Annapolis, Maryland on June 25-28, 2013, and at the Australian Center for Ecological Analysis and Synthesis (ACEAS) on Dec. 9-12, 2013. Seed funding was provided by a grant from the Keck Foundation via NAFKI (National Academy Keck Futures Initiative). The views expressed in this paper are those of the authors and do not necessarily reflect the views or policies of the United States
Environmental Protection Agency. We thank the following two anonymous reviewers for helpful comments on earlier drafts.

\section{References}

Arkema, K., Samhouri, J., 2012. Linking ecosystem health and services to inform marine ecosystem-based management. Am. Fish. Soc. Symp. 79, 9-25.

Axelrod, R., Hamilton, W.D., 1981. The evolution of cooperation. Science 211, 1390-1396.

Baran, N.M., Sapienza, P., Zingales, L., 2010. Can we infer social preferences from the lab? Evidence from the Trust Game. National Bureau of Economic Research No. w15654

Bogost, Ian, 2007. Persuasive Games: The Expressive Power of Videogames. MIT Press, Cambridge, MA.

Boumans, R., Costanza, R., Farley, J., Wilson, M.A., Portela, R., Rotmans, J., Villa, F., Grasso, M., 2002. Modeling the dynamics of the integrated earth system and the value of global ecosystem services using the GUMBO model. Ecol. Econ. 41, 529-560.

Castronova, E., Williams, D., Shen, C., Ratan, R., Xiong, L., Huang, Y., Keegan, B., 2009. As real as real? Macroeconomic behavior in a large-scale virtual world. New Media Soc. 11 (5), 685-707.

Colombo, S., Hanley, N., Christie, M., 2011. What are the consequences of ignoring attributes in choice experiments? An application to ecosystem service values. University of Stirling Economics Discussion Paper.

Costanza, R., Shrum, W., 1988. The effects of taxation on moderating the conflict escalation process: an experiment using the dollar auction game. Soc. Sci. Q. 69, 416-432.

Costanza, R., dArge, R., de Groot, R., Farber, S., Grasso, M., Hannon, B., Limburg, K., Naeem, S., Oneill, R.V., Paruelo, J., Raskin, R.G., Sutton, P., van den Belt, M., 1997. The value of the world's ecosystem services and natural capital. Nature 387, 253-260.

Costanza, R., Voinov, A., 2003. Landscape Simulation Modeling: A Spatially Explicit. Dynamic Approach. Springer, New York.

Craft, C., Clough, J., Ehman, J., Joye, S., Park, R., Pennings, S., Guo, H., Machmuller, M., 2009. Forecasting the effects of accelerated sea-level rise on tidal marsh ecosystem services. Front. Ecol. Environ. 7 (2), 73-78.

De Lucia, A., Francese, R., Passero, I., Tortora, G., 2009. Development and evaluation of a virtual campus on second life: the case of SecondDMI. Comput. Educ. 52, 220-233.

Farber, S.C., Costanza, R., Wilson, M.A., 2002. Economic and ecological concepts for valuing ecosystem services. Ecol. Econ. 41, 375-392.

Fiore, S.M., Harrison, G.W., Hughes, C.E., Rutström, E.E., 2009. Virtual experiments and environmental policy. J. Environ. Econ. Manag. 57, 65-86.

Gentile, D.A., Anderson, C.A., Yukawa, S., Ihori, N., Saleem, M., Ming, L.K., Sakamoto, A., 2009. The effects of prosocial video games on prosocial behaviors: international evidence from correlational, longitudinal, and experimental studies. Personal. Soc. Psychol. Bull. 35 (6), 752-763.

Griswold, Ann 2013. High-stakes game of oil use. In: Proceedings of the National Academy of Sciences 110.8, p. 2685.

Heckbert, S., Bishop, I., 2011. Empirical calibration of spatially explicit agent-based models. In: Marceau, D., Benenson, I. (Eds.), Advanced Geosimulation. Bentham, pp. 92-110.

Heckbert, Scott, 2013. MayaSim: an agent-based model of the ancient maya socialecological system. J. Artif. Soc. Soc. Simul. 16 (4), $11\langle$ http://jasss.soc.surrey.ac. uk/16/4/11.html $\rangle$.

Janssen, M., Holahan, R., Lee, R., Ostrom, E., 2010. Lab Experiments for the study of Social-Ecological Systems. Science 328, 613-617.

Liu, S., Stern, D.I., 2008. A meta-analysis of contingent valuation studies in coastal and near-shore marine ecosystems. MPRA, 11608.

Manson, S.M., Evans, T., 2007. Agent-based modeling of deforestation in southern Yucatan, Mexico, and reforestation in the Midwest United States. Proc. Natl. Acad. Sci. 104, 20678-20683.

Millennium Ecosystem Assessment (MEA), 2005. Ecosystems and Human WellBeing: Synthesis. Island Press, Washington, DC.

Nelson, et al., 2009. Projecting global land-use change and its effect on ecosystem service provision and biodiversity with simple models. Front. Ecol. Environ. 7 (1), 4-11.

Ostrom, E., Gardner, R., Walker, J., 1994. Rules, Games, and Common-Pool Resources. University of Michigan Press.

Rustagi, Devesh, Stefanie, Engel, Michael, Kosfeld, 2010. Conditional cooperation and costly monitoring explain success in forest commons management. Science 330 (6006), 961-965.

Slovic, P., 1995. The construction of preference. Am. Psychol. 50, 364-371.

Verutes, G.M., Rosenthal, A., 2014. Using simulation games to teach ecosystem service synergies and trade-offs. Environ. Pract. 6, 194-204.

Von Neumann, J., Morgenstern, O., 1953. 3rd Ed. Theory of Games and Economic Behavior, 044. Princeton University Press, Princeton, NJ.

Wilson, M., Carpenter, S., 1999. Economic valuation of freshwater ecosystem services in the United States 1971-1997. Ecol. Appl. 9, 772-783. 